Research article

\title{
Pseudomonas putida and Bacillus amyloliquefaciens alleviates the adverse effect of pesticides and poise soil enzymes activities in chickpea (Cicer arietinum L.) rhizosphere
}

\author{
Manoj Kumar ${ }^{1,2}$, Mohd Aslam Yusuf ${ }^{2}$, Puneet Singh Chauhan ${ }^{1}$, \\ Manisha Nigam ${ }^{3}$ and Manoj Kumar ${ }^{1 *}$ \\ ${ }^{1}$ Division of Plant Microbe Interactions, CSIR-National Botanical Research Institute, Rana Pratap Marg, \\ Lucknow-226001, Uttar Pradesh, India \\ ${ }^{2}$ Department of Bioengineering, Integral University, Lucknow-226026, Uttar Pradesh, India \\ ${ }^{3}$ Department of Biochemistry, Hemvati Nandan Bahuguna, Garhwal University, Srinagar, \\ Garhwal-246174, Uttarakhand, India
}

*Corresponding Author: manojyd1234@gmail.com

[Accepted: 17 November 2017]

\begin{abstract}
Pesticide application for disease management is a major action for crop protection from last seven decades. The repeated application of pesticide is the most important cause of the reduction in microbial population. Soil microorganisms play an important role in efficient acquisition and transportation of nutrients to plant. Pesticides leached in soil disturb the activities of soil enzymes, such as $\beta$-glucosidase, dehydrogenase, phosphatases, protease and urease secreted by these microorganisms. This drastically reduces nutrient availability to the plants and soil fertility. In vitro experimental studies revealed that our PGPR (Pseudomonas putida and Bacillus amyloliquefaciens) have the ability to tolerate pesticides at concentrations such as Carbendazim $(0.512 \%)$, Imidacloprid (3.27\%) and Glyphosate (3.27\%). We have observed an increase in PGP activities like IAA production, exopolysachchride production, biofilm synthesis, phosphate solubilization and siderophore production on the addition of pesticides at concentrations below there threshold values, on the contrary reduction in activities was noticed above these values. Soil enzymes activities from chickpea rhizosphere without PGPR inoculation showed variability on the application of pesticides whereas activities were found normal or increased with PGPR inoculation and pesticides application. Thus PGPR remains panacea for soils by managing adverse effects of pesticide application. Hence our results concluded that $P$. putida and B. amyloliquefaciens have the ability to reduce the negative impact of three pesticides and poise soil enzymes activities. Hence our PGPR acts as efficient biofertilizers to improve soil fertility and soil health.
\end{abstract}

Keywords: Carbendazim - Chickpea - Glyphosate - Imidacloprid - PGPR - Soil enzymes.

[Cite as: Kumar M, Yusuf MA, Chauhan PS, Nigam M \& Kumar M (2017) Pseudomonas putida and Bacillus amyloliquefaciens alleviates the adverse effect of pesticides and poise soil enzymes activities in chickpea (Cicer arietinum L.) rhizosphere. Tropical Plant Research 4(3): 405-418]

\section{INTRODUCTION}

Chickpea (Cicer arietinum L.) is the third most important legume crop. India produces nearly $75 \%$ of world's chickpea production. Often it is grown after cereal crops to interrupt onset of disease, weed control and improve soil nitrogen content. Seed is the main edible part of the plant and is a rich source of carbohydrate (48.2-67.6\%), protein (12.4-31.5\%) and fat (6\%) especially for the vegetarian people (Rao 2010). Chickpea can fix atmospheric nitrogen through its symbiotic association with Rhizobium species thus helping in enhancing the soil quality. Pests involving insects, fungi and weeds are the major biotic factors which reduce crop yield by affecting the root-shoot growth. The key pest that limits pulses improvement in India comprises pod borers, foliar diseases and weeds. Pesticides uses remain minimal for pulses in India (Reddy \& Reddy 2010). In a survey of pesticide use on pulse crop in four regions revealed that use of fungicides is $4-12 \%$, herbicides $0-24 \%$ 
and insecticides 16-50\% (IIPR 2010-11). To increase pulses production for the ever-increasing population application of chemical pesticides ensured high crop productivity.

Pesticides are substances or mixtures of substances proposed for destroying, preventing, mitigating or repelling pests (Grube et al. 2011). Pesticide application to the crop exposes soil and its microflora to its adverse effects. These includes pesticide interaction with soil enzymes (Gianfreda \& Rao 2008), its binding with the active site of the soil enzymes affecting their catalytic activities (Tabatabai 1994) and/or pesticides utilized as a nutrient source by soil microbes resulting in biodiversity changes. A number of pesticides stimulate the growth of microorganisms, but other pesticides inhibit or have no effects on microorganisms when used at normal rates. We have included three pesticides i.e. Carbendazim, Imidacloprid and Glyphosate in our study. Glyphosate (N(phosphonomethyl) glycine) a herbicide was commercialized in 1974. It has been demonstrated that the glyphosate can impact the rhizosphere community (Sheng et al. 2012) and rhizosphere processes (Ahemad \& Kibret 2013). Among herbicides glyphosate [N-(phosphonomethyl) glycine] is the non-selective systemic herbicide most commonly used in agricultural practices on a global scale (Mijangos et al. 2009). Once glyphosate is absorbed by foliage, it is transported throughout the whole plant via the phloem to the growing tissues such as the shoot and root meristems. This mechanism results in glyphosate being exuded into rhizosphere soil (Neumann et al. 2006). Glyphosate [N-(phosphonomethyl) glycine] inhibits the enzymatic activity of 5-enolpyruvoyl-shikimate-3-phosphate synthase (EPSPS) in the shikimate pathway, thus preventing the synthesis of aromatic amino acids needed for plant growth and survival (Duke 2005). Carbendazim (methyl benzImizol-2-yl carbamate) is a systemic fungicide. It acts by interfering with microtubule formation during mitosis in fungal cells. The repeated use of pesticides into the crops may reach into the soil which disturbs local metabolism or enzymatic activities (Engelen et al. 1998, Liu et al. 2008, Hussain et al. 2009). Negative impacts of pesticides on soil enzymes such as dehydrogenase, oxidoreductases and hydrolase activities have been widely reported in the literature (Perucci \& Scarponi 1994, Malkomes \& Dietze 1998, Monkiedje \& Spiteller 2002, Menon et al. 2005, Caceres et al. 2009). Imidacloprid ( $N$-\{1-[(6-Chloro-3-pyridyl) methyl]-4,5-dihydroImizol2 -yl $\}$ nitramide) is a systemic insecticide which works as insect neurotoxin of neonicotinoids class and acts on the central nervous system of insects. It is much low toxic for mammals also. Imidacloprid has become a popular insecticide worldwide due to systemic mode of action and low toxicity to humans and its use in field crops, vegetables and ornamentals (Ishaaya \& Horowitz 1988, Matsuda et al. 2001, Nauen \& Denholm 2005) Imidacloprid is registered in approximately 120 countries and is used on over 140 different agricultural crops (Buffin 2005) including chickpea.

Soil fertility is the result of the effective and cumulative role played by beneficial microbes in the soil. Pesticides uses have an adverse effect on useful microorganisms in rhizoshpere. Vice versa microbes have the ability to degrade pesticides and nullify influence of pesticides on microbial diversity in soil. The knowledge of these processes and extent of its ability to minimise losses by pesticides are still not well studied. To prevent the adverse effect of pesticides, rhizobial inoculants often used as bio-fertilizer and have the ability to maintains the nutrients and degrade the pesticides when applied to soil/seeds of legumes (Lo 2010). Since plant growth promoting rhizobacteria (PGPR) play positive role on plant health through a variety of mechanisms, including mineralization of nutrients, suppression of disease, improving plant stress tolerance and production of phytohormones (Berendsen et al. 2012, Figueiredo et al. 2011, Gupta et al. 2000). Soil enzyme activities are the direct reflection of the soil community to metabolic requirements and available nutrients. The interaction between soil components and pesticides influences the biochemical activity of bacteria. Telluric fungi (Hernandez-Rodriguez et al. 2006, Ronhede et al. 2007) and bacteria (Dong et al. 2005) are able to degrade or mineralize pesticides by enzymatic reactions. There is evidence that soil enzymes may provide valuable information on the transformation of pesticides in soils (Gianfreda \& Baollag 1994, Kalam et al. 2004, GilSotres et al. 2005, Hussain et al. 2009). The enzymes are active outside the cell where they catalyze reactions to break down the structure of the nutrient source to make it more accessible, but pesticides affect the soil enzyme and disturb the cycle. In India Maharashtra, Andhra Pradesh (including Telangana \& Seemandhra), and Punjab are top three states which contribute about $45 \%$ consumption of pesticides. Andhra Pradesh is the highest pesticides consumer with $24 \%$ share. Soil enzymes are dehydrogenase, acid/alkaline phosphatase, $\beta$ glucosidase, urease, protease. Decrease urease activity in soil due to the application of pesticides reduces urea hydrolysis, which is generally beneficial, because it helps to maintain nitrogen availability to plants.

In the this paper we have reported that plant growth promoting traits of the bacteria such as biofilm 
formation, mineral phosphate solubilisation, siderophore production, IAA production and EPS formation activity were estimated in presence of different concentrations of Carbendazim (fungicide), Imidacloprid (insecticide) and Glyphosate (herbicide) with the help of standard protocols routinely used in our laboratory. In our study, we have taken chickpea plant (BG-362) to evaluate the PGPR effect in presence of different pesticides on plant growth parameters. For this, we have used the B. amyloliquefaciens (SN13) and P. putida (RA) to see the effect of pesticides on them and Maximum Tolerance Level (MTL) was determined in vitro. In vitro tests were performed to find the interaction between the PGPR and Pesticides, while in vivo tests were performed to see the effects of pesticides on chickpea fortified with PGPR. We also did glasshouse experiments to see the effect of pesticide sprays on soil enzymatic activities of chickpea rhizosphere treated with PGPR.

\section{MATERIALS AND METHODS}

In vitro PGP traits evaluation of PGPR in presence of pesticides

Pseudomonas putida (RA) and Bacillus amyloliquefaciens (SN13) used in the study were procured from the lab depository, Division of plant-microbe interactions, CSIR-NBRI. Pesticides used in this study were Carbendazim (Car), Glyphosate (Gly) and Imidacloprid (Imi). Earlier we have performed in vitro PGP traits evaluation of both the bacterium and their synergistic effect for drought amelioration in chickpea (Kumar et al. 2016).

\section{Assessment of bacterial strains for pesticides tolerance}

The bacterial strains were tested for their pesticide tolerance onto agar plate $4 / 5$ dilution method (Gupta et al. 1994) using nutrient agar medium. The freshly prepared agar plates were spreaded with 48 hrs grown P. putida and B. amyloliquefaciens cultures having $1 \mathrm{OD}$ at $600 \mathrm{~nm}$. These plates were spotted with $10 \mu \mathrm{l}$ of different concentrations of Imi (10 to $2.097 \%$ ), Gly (10 to $0.156 \%$ ) and Car (1 to $0.156 \%$ ) based on recommended spraying concentration in field for disease management for chickpea crop in published literatures (Mishra et al. 2005, Andrabi et al. 2011, Yogeeswarudu \& Venkata-Krishna 2014). Plates were incubated at $28^{\circ} \mathrm{C}$ for $48 \mathrm{hrs}$ and the highest concentration of Car, Imi and Gly supporting bacterial growth were defined as the Maximum Tolerance Level (MTL) (Ahmed \& Khan 2012).

\section{Quantitative estimation of auxin, biofilm and exopolysachharide under pesticides treatments}

Quantification of auxin production by bacterial strains was analysed using modified version (Brick et al. 1991) of method proposed by Gordon \& Weber (1951) using Salkowski's reagent. For IAA production assay 5 $\mathrm{ml}$ of auxin medium was supplemented with varying concentrations viz. 2.09\%, 3.2\%, 4.09\%, 5.14\% Imi, $2.62 \%, 2.09 \%, 3.27 \%, 4.09 \%$ Gly and $0.32 \%, 0.4 \%, 0.51 \%, .6 \%$ Car respectively in culture vials in triplicates. Now a set of these culture vials were added with a single isolated colony of RA and a separate set with SN13. Cultures tubes were incubated in a rotatory shaker at $180 \mathrm{rpm}$ at $28^{\circ} \mathrm{C}$. After 5 days, $5 \mathrm{ml}$ culture from each treatment was centrifuged at 10,000 rpm for $15 \mathrm{~min} .2 \mathrm{ml}$ of supernatant was taken in fresh test tubes and $100 \mu \mathrm{l}$ of $10 \mathrm{mM}$ of Orthophosphoric acid followed by $4 \mathrm{ml}$ of Salkowski's reagent was added. The mixture was incubated at $28^{\circ} \mathrm{C}$ in dark for one hour. The absorbance of the samples resulting orange colour was measured at $530 \mathrm{~nm}$ in UV spectrophotometer (Thermo Fisher Scientific, USA). Reagent mixture without culture was taken as blank.

Biofilm formation assay was performed by inoculating bacterial strains in NB media. Take $5 \mathrm{ml}$ of $48 \mathrm{hrs}$ grown culture at $28^{\circ} \mathrm{C}$ in test tubes supplemented with above-mentioned pesticides concentrations in triplicate. Now, $250 \mu 1$ of this culture was transferred in a microtiter plate (Tarsons Pvt. Ltd., India) with the help of pipette and overnight incubated at $30^{\circ} \mathrm{C}$ for $24 \mathrm{hrs}$. Discard the culture and gently tapped on filter paper. Stain with $250 \mu \mathrm{l}$ of $0.1 \%$ crystal violet then incubate at room temperature for $30 \mathrm{~min}$. Crystal violet was removed by washing with distilled water. Finally absorbed crystal violet extracted with $250 \mu 1$ of $95 \%$ ethyl alcohol for 1 hour. O.D was taken at $595 \mathrm{~nm}$ (Khan et al. 2012).

Exopolysachharide production assay was performed according to Dubois et al. (1956). Bacterial strains were grown in $50 \mathrm{ml}$ Luria Bertani broth with $5 \%$ sucrose supplemented with different concentration of pesticides and incubated for 5 days at $28^{\circ} \mathrm{C}$ on a shaker at $100 \mathrm{rpm}$. Take $10 \mathrm{ml}$ of this 5 days grown culture in $50 \mathrm{ml}$ falcon tubes and add an equal volume of ethanol (absolute). Samples were overnight incubated at $4^{\circ} \mathrm{C}$. Centrifuge the tubes at $10,000 \mathrm{rpm}$ for $10 \mathrm{mins}$ at $4^{\circ} \mathrm{C}$, dry the pellet in hot air oven. Add $0.5 \mathrm{ml}$ saline, $0.5 \mathrm{ml}$ phenol (5\%) and $1 \mathrm{ml} \mathrm{H}_{2} \mathrm{SO}_{4}$ (36\%). Mix it and place it in a dark for 30-60 min. Absorbance was measured at $490 \mathrm{~nm}$. 
Qualitative estimation of phosphate solubilization and siderophore production under pesticides treatments

Phosphate solubilisation assay was performed using NBRIP medium (Nautiyal, 1999). A single colony of SN13 and RA was inoculated in each test tube containing $5 \mathrm{ml}$ specially formulated medium NBRIP supplemented with varying concentration of three pesticides in triplicates. Inoculated tubes were incubated for 7 days at $28^{\circ} \mathrm{C}$ in a rotatory shaker at $180 \mathrm{rpm}$ and daily observed for change in phosphate solubilizing activity visually. Tricalcium phosphate (TCP) solubilizing activity by SN13 and RA in the presence of three pesticides was observed for color change. Siderophore production was tested by CAS (Chrome azurol S) assay (Meyer \& Abdallah 1978). RA and SN13 culture were inoculated in NB medium supplemented with different pesticides. CAS agar media plate was spot inoculated with $10 \mu$ of the overnight grown bacterial culture of RA and SN13 containing pesticides. These plates were incubated at $28^{\circ} \mathrm{C}$ for 5 days. Siderophore production was detected by observing the yellow-orange halo zone.

\section{Seed bacterization, sowing, growth parameter and pesticide spray}

Chickpea seeds cultivar viz. BG362 was used for this experiment. Seeds bacterization was performed according to Nautiyal (1997). The overnight grown culture of RA and SN13 were used separately for seeds bacterization. Plastic pots $(24 \mathrm{~cm} \times 12 \mathrm{~cm} \times 12 \mathrm{~cm})$ were filled with sterile soil composition $(50 \%$ soil, $25 \%$ vermiculate, $25 \%$ coccopit, and $10 \%$ sand). Total 30 seeds for each treatment RA, SN13 and control were taken. Five seeds per pot were sown at $5 \mathrm{~cm}$ depth in $1.2 \mathrm{~kg}$ soil. Pots were kept in the glass house at temperature $24 \pm 2{ }^{\circ} \mathrm{C}$ and 16: 8 light and dark conditions. The plants were irrigated with sterilized water. Plant growth parameters were recorded 30 days after sowing. RA and SN13 inoculated plants along with control were harvested in triplicates before pesticides spray for growth parameters like shoot, root length, fresh weight and dry weight. These plants were dried in hot air oven at $65^{\circ} \mathrm{C}$ for 5 days. After this shoot and root dry weight were recorded. Pesticides spray on chickpea plants was performed at different concentrations of Car, Imi and Gly choosen from MTL results (Ahmed and Khan 2012). For pesticides spray 1\% Car (50\% WP), 10\% Gly (41\% WP) and $10 \%$ Imi (17.8\% S.L.) were sprayed on chickpea plants. The first spray was done after 30 days from sowing of chickpea seeds and second sprays after 25 days from the first spray.

\section{Soil enzymes assay}

Soil enzymes assay were performed after first and second spray of different pesticides from chickpea rhizosphere soil. To determine the positive or negative effect of pesticides on soil enzymes activity like dehydrogenase, acid/alkaline phosphate, urease activity, $\beta$-glucosidase activity and protease activity were analysed. This experiment was performed using three biological and three technical replicates. The data were statistically analyzed using SPSS 16.0 software (Statistical Package for the Social Sciences 16.0, SPSS Inc., USA, 1999) for DMRT (Duncan's Multiple Range Test).

The activity of Dehydrogenase enzyme was analysed according to Alef \& Nannipieri (1995). Weigh 5 gm soil in $50 \mathrm{ml}$ tubes, containing $5 \mathrm{ml}$ of $0.8 \%$ Triphenyl tetrazolium chlororide (TTC) solution. Tubes will be tightly sealed and incubated at $28^{\circ} \mathrm{C}$ for $24 \mathrm{hrs}$ in the dark on a shaker at $120 \mathrm{rpm}$. A control contains $5 \mathrm{ml}$ Tris$\mathrm{HCl}$ buffer (without TTC) will set up. After incubation, $40 \mathrm{ml}$ acetone was added in each tube (intermediately shaken) and again incubated at RT for 2 hrs in the dark with manual shaking after every 10-15 min. Later, $3 \mathrm{ml}$ from each tube was transferred falcon tubes, centrifuged and the absorbance of the supernatant was recorded at the $540 \mathrm{~nm}$. Soil phosphatase activities were analysed according to Tabatabai \& Bremner (1969) using pnitrophenyl phosphate solution as the substrate. One gm of soil taken in $50 \mathrm{ml}$ flask and add $0.25 \mathrm{ml}$ toluene. Take $4 \mathrm{ml}$ Modified Universal Buffere (MUB) ( $\mathrm{pH} 6.5$ for acid phosphates and $\mathrm{pH} 11$ for the alkaline phosphates) and add $1 \mathrm{ml}$ p-nitrophenyl phosphate $(15 \mathrm{mM})$. Mix solution properly and incubate at $37^{\circ} \mathrm{C}$ for 1 hr. After incubation, add $1 \mathrm{ml}$ of $\mathrm{CaCl}_{2}(0.5 \mathrm{M})$ and $4 \mathrm{ml}$ of $\mathrm{NaOH}(0.5 \mathrm{M})$. For control, add $1 \mathrm{ml}$ of PNPP solution after the additions of $\mathrm{CaCl}_{2}(0.5 \mathrm{M})$ and $4 \mathrm{ml}$ of $\mathrm{NaOH}(0.5 \mathrm{M})$ immediately before filtration of the soil suspension. Mix the content properly and filter the soil suspension through whattman filter paper. Measure the absorbance at $400 \mathrm{~nm}$.

$\beta$-glucosidase activity was examined by taking one gm soil in $50 \mathrm{ml}$ Erlenmeyer flask, add $0.25 \mathrm{ml}$ of toluene, $4 \mathrm{ml}$ of MUB solution and $1 \mathrm{ml}$ p-nitrophenyl- $\beta-\mathrm{D}$ glucoside (PNG) solution, stopper the flask and mixed properly and incubate at $37^{\circ} \mathrm{c}$ for $1 \mathrm{hr}$. After the incubation, add $1 \mathrm{ml}$ of $\mathrm{CaCl}_{2}$ solution, $4 \mathrm{ml}$ tris-buffer (pH 12) swirl the flask and immediately take a filter through the Whatman filter paper (Eivazi \& Tabatabai 1988). Measure the colour intensity at $400 \mathrm{~nm}$ (if intensity comes high then we dilute the filtrate with trisbuffer). For blank preparation, add substrate PNG before adding $\mathrm{CaCl}_{2}$ and tris-buffer. The activity of urease www.tropicalplantresearch.com 
enzyme was assayed according to (Kandeler \& Gerber 1988). Five gm of moist soil was taken in Erlenmeyer flask and $2.5 \mathrm{ml}$ urea solution was added. Stopper the flask and incubate it, add $50 \mathrm{ml}$ of $\mathrm{KCl}$ solution (74.6 $\mathrm{g}$ $\mathrm{KCl}$ and $10 \mathrm{ml}$ of $1 \mathrm{M} \mathrm{HCl}$ to make 1 litre solution) and shake the flask for $3 \mathrm{~min}$. After the filtering the resulting suspension, filtrates were analyzed for the ammonium content. Take a $1 \mathrm{ml}$ filtrate in $50 \mathrm{ml}$ flask, then add $9 \mathrm{ml}$ DW, $5 \mathrm{ml}$ of $\mathrm{Na}$ - salicylate/ $\mathrm{NaOH}$ solution and $2 \mathrm{ml}$ of the sodium dichloro isocyanurate solution and allow standing at RT for $30 \mathrm{~min}$ prior to measure O.D at $690 \mathrm{~nm}$. For blank take $10 \mathrm{ml} \mathrm{DW}$ and add $2.5 \mathrm{ml}$ urea solution, $5 \mathrm{ml}$ of $\mathrm{Na}$ - salicylate/ $\mathrm{NaOH}$ solution, and $2 \mathrm{ml}$ of sodium dichloro isocyanurate solution at the end of incubation and immediately before $\mathrm{KCl}$ addition. Protease activity was analysed by taking one gm of moist soil in a centrifuge tube, add $5 \mathrm{ml}$ tris-buffer and $5 \mathrm{ml}$ of Na-Caseinate solution stopper the tubes and mix properly, incubated at $50^{\circ} \mathrm{C}$ for $2 \mathrm{hrs}$ on the shaker bath. After incubation adds $5 \mathrm{ml} 15 \%$ TCA solution and mix properly. Centrifuge the soil suspension at 10,000-12,000 rpm for $10 \mathrm{~min}$. Take a $5 \mathrm{ml}$ of the clear supernatant into the fresh tubes and add $7.5 \mathrm{ml}$ alkaline reagent, incubate it at RT for $15 \mathrm{~min}$. Finally add, $5 \mathrm{ml}$ of folin's reagent. Filter the mixture through the filter paper and measure the absorbance at $700 \mathrm{~nm}$. To prepare a control, add $5 \mathrm{ml}$ of Na-Caseinate solution, incubate and finally adding the TCA solution (Ladd \& Butler 1972).

\section{Colony forming unit (CFU) assay}

CFU assay of rhisophere soil was performed on 24, 48 and $72 \mathrm{hrs}$ after the first and second pesticides spray. CFU was done by taking the rhizosphere soil samples of all treatments along with control to determine the effect of pesticides on viable microbial colonies. One gram soil sample of each treatment was taken in falcon and used to prepare a suspension of $10 \mathrm{ml}$ using $0.85 \% \mathrm{NaCl}$ saline, then vortex it and allow rotating at $28^{\circ} \mathrm{C}$ on a rotator shaker at $180 \mathrm{rpm}$ for one hour and performed spotting on NA plates. The numbers of colonies in different dilutions were determined by average $\mathrm{CFU} / \mathrm{ml}$ values populations in triplicates per treatment and observe the effect of pesticides on colonies. CFU measurement was performed in biological triplicates and their technical triplicates.

\section{Functional microbial diversity analysis using Biolog}

Functional diversity of the soil microbial community was characterized using community level physiological profiles generated by carbon source utilisation pattern on Biolog EcoPlate (BIOLOG, Hayward, CA, USA). Microbial diversity analysis was performed for diversity indices like Shannon diversity, evenness, Simpson diversity and McIntosh diversity and evenness. Rhizosphere soil samples were used for biolog assay. One gram soil was dissolved in $10 \mathrm{ml}$ of $0.85 \%$ of $\mathrm{NaCl}$ saline and incubated at $28^{\circ} \mathrm{C}$ in rotator shaker for one hour at 200 rpm. From this, 125 microlitre suspension cultures was added to each well on Biolog Eco plate. Samples were loaded in triplicate and incubated at $28^{\circ} \mathrm{C}$ in the incubator. Absorbance was taken at $590 \mathrm{~nm}$ after $24 \mathrm{hrs}$ interval till 10 days.

\section{RESULTS}

Maximum tolerance level (MTL) of pesticides by bacterial strains

The highest concentration of Car (0.512\%), Imi (3.27\%) and Gly (3.27\%) that supported the growth of RA and SN13 is referred as MTL (Table 1). These MTL values results were observed after 24 and 48 hrs from inoculation of pesticides on PGPR grown plates in vitro. There was similar size of hallo zone formation after 24 and $48 \mathrm{hrs}$ of pesticide inoculation in case of both PGPR.

\section{PGP traits evaluation of bacteria in presence of pesticides}

Quantitative estimation of auxin, EPS and biofilm production by RA and SN13 in presence of different concentrations of pesticides has been performed. Auxin production by RA with $0.4 \%$ Car $\left(52.17 \mu \mathrm{g} . \mathrm{ml}^{-1}\right)$, 3.27\% Imi $\left(56.09 \mu \mathrm{g} \cdot \mathrm{ml}^{-1}\right)$ and 3.27\% Gly $\left(52.69 \mu \mathrm{g} \cdot \mathrm{ml}^{-1}\right)$ were found maximum whereas SN13 produced maximum auxin at $0.4 \% \mathrm{Car}\left(26.39 \mu \mathrm{g} \cdot \mathrm{ml}^{-1}\right), 3.27 \% \mathrm{Imi}\left(29.40 \mu \mathrm{g} \cdot \mathrm{ml}^{-1}\right)$ and $2.62 \% \mathrm{Gly}\left(26.95 \mu \mathrm{g} \cdot \mathrm{ml}^{-1}\right)(\mathrm{Table}$ 2). EPS production was measured in presence of pesticides showed its highest production by RA at $0.51 \%$ Car $\left(306.80 \mu \mathrm{g} . \mathrm{ml}^{-1}\right), 3.2 \% \mathrm{Imi}\left(330.20 \mu \mathrm{g} . \mathrm{ml}^{-1}\right)$ and at 3.27\% Gly $\left(287.52 \mu \mathrm{g} . \mathrm{ml}^{-1}\right)$ concentration in vitro. Similarly, EPS production by SN13 was maximum at $0.4 \% \mathrm{Car}\left(306.80 \mu \mathrm{g} \cdot \mathrm{ml}^{-1}\right), 3.2 \% \mathrm{Imi}\left(359.67 \mu \mathrm{g} \cdot \mathrm{ml}^{-1}\right)$ and at $3.27 \%$ Gly $\left(309.62 \mu \mathrm{g} \cdot \mathrm{ml}^{-1}\right)$. Biofilm production for both the bacteria was found highest at $0.4 \%$ Car, $3.2 \%$ Imi and $3.27 \%$ Gly concentrations. On further increasing concentrations of these pesticides, decrease in auxin, EPS and biofilm production was observed by RA and SN13.

Qualitative estimation of phosphate solubilisation and siderophore production by RA and SN13 in presence of pesticides was performed and found promising results. Phosphate solubilisation (Fig. 1A) and siderophore www.tropicalplantresearch.com 
production (Fig. 1B) was found the maximum in RA and SN13 samples containing Imi compared to control sample. Car treated RA and Gly treated SN13 produced lesser siderophore activity than other treatments.

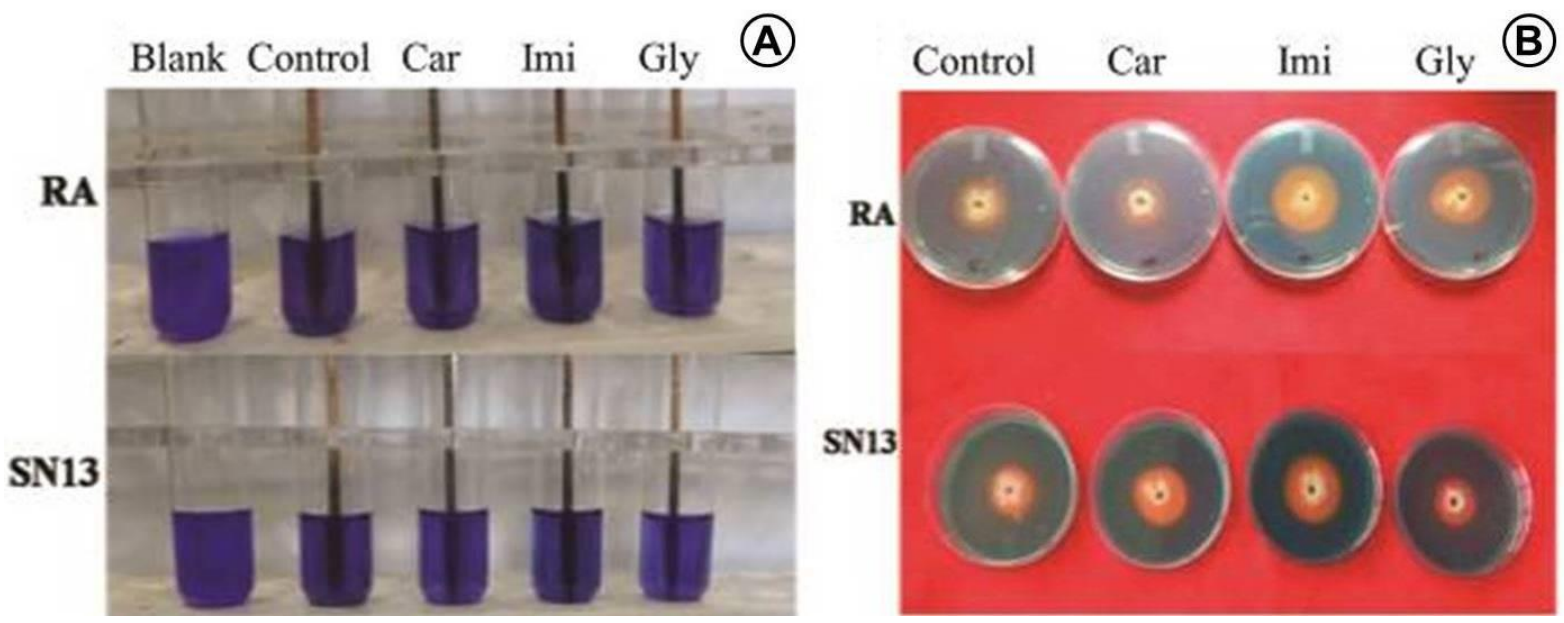

Figure 1. Qualitative estimation of in vitro PGP traits in presence of pesticides: A, Phosphate solubilisation by Pseudomonas putida (RA) and Bacillus amyloliquefaciens (SN13), Blank (without inoculation of PGPR), control (bacteria inoculated sample), Car (bacteria inoculated with carbendazim), Imi (bacteria inoculated with Imidacloprid), Gly (bacteria inoculated with glyphosate); B, Siderophore production by RA and SN13. [Control (bacteria inoculated sample), Car (bacteria inoculated with carbendazim), Imi (bacteria inoculated with Imidacloprid), Gly (bacteria inoculated with glyphosate)]

Table 1. Maximum tolerance level (MTL) values of three pesticides applied to 24 and 48 hrs grown Pseudomonas putida and Bacillus amyloliquefaciens.

\begin{tabular}{|c|c|c|c|c|c|c|}
\hline \multirow[t]{2}{*}{ S. No. } & \multirow[t]{2}{*}{ Pesticides } & \multirow[t]{2}{*}{ Concentration (\%) } & \multicolumn{2}{|c|}{ At 24 hrs } & \multicolumn{2}{|c|}{ At 48 hrs } \\
\hline & & & $\mathbf{R A}$ & SN13 & RA & SN13 \\
\hline \multirow[t]{8}{*}{1} & Carbendazim $(0.2-1 \%)$ & 1 & - & - & - & - \\
\hline & & 0.8 & - & - & - & - \\
\hline & & 0.64 & - & - & - & - \\
\hline & & 0.512 & - & - & - & - \\
\hline & & 0.409 & + & + & + & + \\
\hline & & 0.327 & + & + & + & + \\
\hline & & 0.209 & + & + & + & + \\
\hline & & 0.262 & + & + & + & + \\
\hline \multirow[t]{8}{*}{2} & Glyphosate (2-10\%) & 10 & - & - & - & - \\
\hline & & 8 & - & - & - & - \\
\hline & & 6.4 & - & - & - & - \\
\hline & & 5.12 & - & - & - & - \\
\hline & & 4.096 & - & - & - & - \\
\hline & & 3.27 & + & + & + & + \\
\hline & & 2.62 & + & + & + & + \\
\hline & & 2.09 & + & + & + & + \\
\hline \multirow[t]{8}{*}{3} & Imidacloprid (2-10\%) & 10 & - & - & - & - \\
\hline & & 8 & - & - & - & - \\
\hline & & 6.4 & - & - & - & - \\
\hline & & 5.12 & - & - & - & - \\
\hline & & 4.096 & - & - & - & - \\
\hline & & 3.27 & + & + & + & + \\
\hline & & 2.621 & + & + & + & + \\
\hline & & 2.097 & + & + & + & + \\
\hline
\end{tabular}

Note: +, The tolerance of different pesticides by RA and SN13; -, The non-tolerance of different pesticides by RA and $\mathrm{SN} 13$ in vitro

Chickpea plant growth parameters

Chickpea cultivar (BG-362) was evaluated for plant growth promotion to see the effect of PGPR. Results (Table 3) clearly revealed that inoculation with RA and SN13 has significantly enhanced the plant biomass like root and shoot length, the fresh and dry weight of root and shoot of chickpea plant as compared to un-inoculated control. 


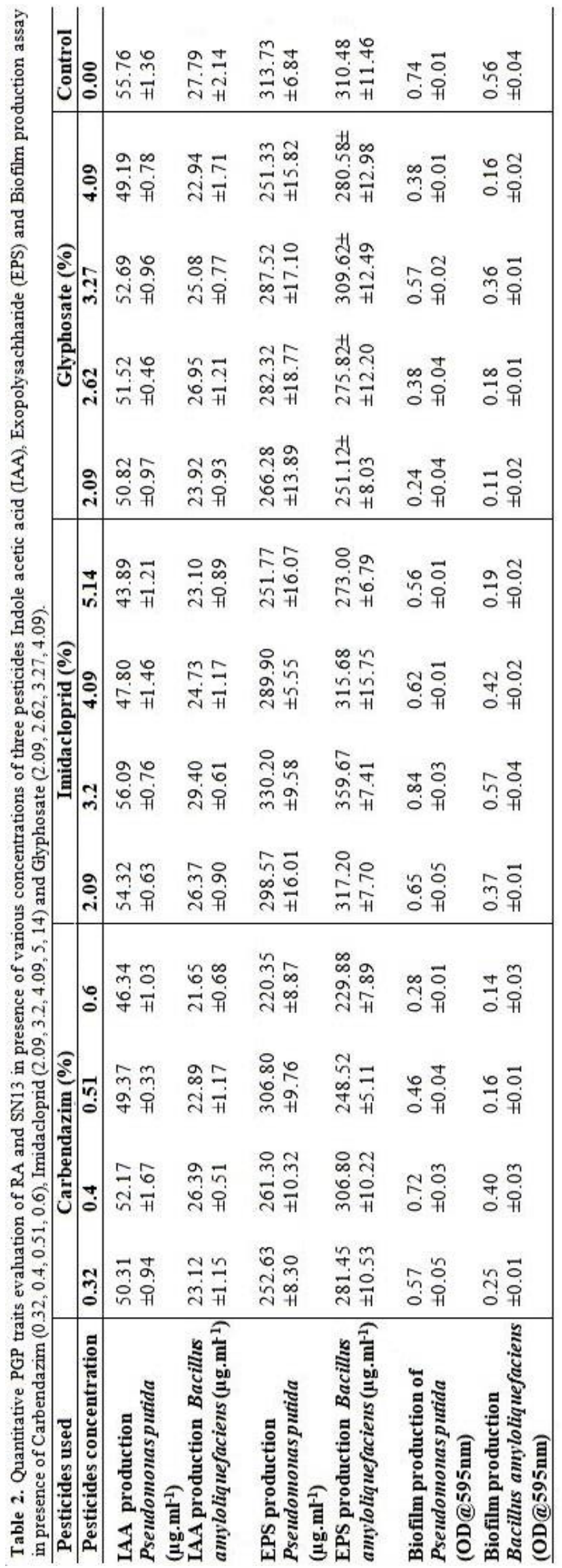


Table 3. Plant growth parameters in chickpea treated with Pseudomonas putida (RA) and Bacillus amyloliquefaciens (SN13) and under control condition measured 30 days after sowing.

\begin{tabular}{lrrrrrrr}
\hline Treatments & $\begin{array}{r}\text { Root length } \\
(\mathbf{c m})\end{array}$ & $\begin{array}{r}\text { Shoot length } \\
(\mathbf{c m})\end{array}$ & $\begin{array}{r}\text { Fresh weight } \\
\text { root } \mathbf{( g m})\end{array}$ & $\begin{array}{r}\text { Fresh weight } \\
\text { shoot }(\mathbf{g m})\end{array}$ & $\begin{array}{r}\text { Dry weight } \\
\text { root }(\mathbf{g m})\end{array}$ & $\begin{array}{r}\text { Dry weight } \\
\text { shoot }(\mathbf{g m})\end{array}$ & $\begin{array}{r}\text { R/S DW } \\
\text { ratio }\end{array}$ \\
\hline Control & $27.67 \pm 2.33$ & $19.50 \pm 0.29$ & $0.63 \pm 0.16$ & $1.64 \pm 0.18$ & $0.08 \pm 0.01$ & $0.25 \pm 0.02$ & 0.31 \\
SN13 & $49.33 \pm 2.03$ & $24.33 \pm 0.33$ & $0.67 \pm 0.01$ & $2.08 \pm 0.04$ & $0.09 \pm 0.00$ & $0.28 \pm 0.00$ & 0.32 \\
RA & $30.00 \pm 2.08$ & $23.67 \pm 1.33$ & $0.66 \pm 0.03$ & $1.91 \pm 0.18$ & $0.08 \pm 0.01$ & $0.25 \pm 0.02$ & 0.34 \\
\hline
\end{tabular}

Soil enzymes activity under pesticide treatments

Soil enzymes assay using chickpea rhizosphere soil was performed after first and second spray of pesticides. Dehydrogenase, alkaline/acid phosphatase, $\beta$-glucosidase, urease and protease activities were performed and found that RA and SN13 poise these activities in soil. Soil enzymes activities were found higher in individually RA and SN13 inoculated samples than control and other treatments. Dehydrogenase activity was inhibited in Car and Gly treated samples whereas Imi didn't affect this activity. Dehydrogenase activity was found induced in samples inoculated with RA and SN13 in presence of these pesticides (Fig. 2A). Acid phosphatase activity was enhanced in Car and Gly treated soil samples whereas activity was inhibited in Imi treated samples (Fig. 2B). RA and SN13 inoculated samples have higher acid phosphatase activity than other samples. RA and SN13 inoculated samples treated with Car, Gly and Imi resulted induced the activity of acid phosphatase. Alkaline
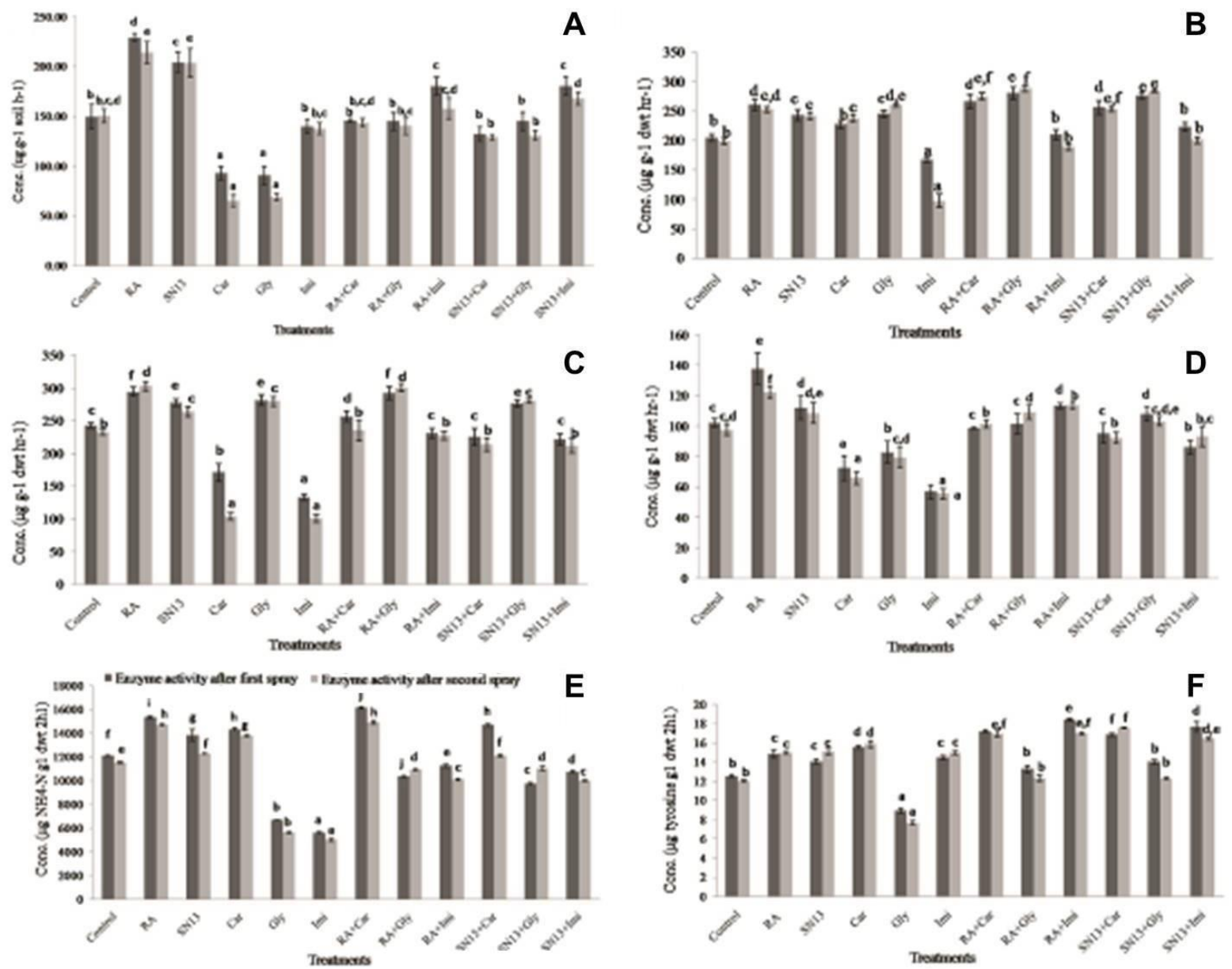

Figure 2. Soil enzymes activity in RA and SN13 inoculated soil samples after pesticides application: A, Dehydrogenase activity; B, Acid phosphatase activity; C, Alkaline phosphatase activity; D, $\beta$-glucosidase activity; E, Urease activity; F, Protease activity. [Control (without treatment), RA (samples inoculated with Pseudomonas putida), SN13 (samples inoculated with Bacillus amyloliquefaciens), Car (samples sprayed with Carbendazim), RA+ Car (samples inoculated with $P$. putida and sprayed with Carbendazim), Gly (samples sprayed with Glyphosate), RA+ Gly (samples inoculated with $P$. putida and sprayed with Glyphosate), Imi (samples sprayed with Imidacloprid), RA+ Imi (samples inoculated with P. putida and sprayed with Imidacloprid), SN13+Car (samples inoculated with B. amyloliquifaciens and sprayed with Carbendazim), SN13+ Gly (samples inoculated with B. amyloliquifaciens and sprayed with Glyphosate), SN13+Imi (samples inoculated with $B$. amyloliquifaciens and sprayed with Imidacloprid), bars represent the standard errors of the means $(\mathrm{n}=3)$. Different letters within column represents significant difference at $(\mathrm{P}=0.05)$ by using DMRT] 
phosphatase activity was inhibited with Car and Imi but stimulated with Gly (Fig. 2C). RA inoculated sample individually as well as RA with Gly treated sample stimulated highest alkaline phosphatase activity. $\beta$ glucosidase activity was inhibited with all three pesticides. This activity was found higher in bacterized samples than control (Fig. 2D). Imi treated sample showing the highly inhibited activity of $\beta$-glucosidase after first and second spray. Sample inoculated with RA alone have highly stimulated this activity. Urease activity was found inhibited by Gly and Imi whereas stimulated with Car (Fig. 2E). RA and SN13 inoculated samples treated with Gly and Imi have enhanced urease activity than only Gly and Imi treated samples. Urease activity was highly induced in RA inoculated soil treated with Car after first and second spray. Protease activity was found stimulated in samples containing Car and Imi whereas highly reduced activity was found in Gly treated soil samples (Fig. 2F). Surprisingly, most of the soil enzymes activities found reduced which we have performed after second application of these three pesticides in comparison with the first application. These results proved that repeated application of pesticides affects soil enzyme activities. Results indicated that RA and SN13 have the ability to tolerate the pesticides and reduced its adverse effect in the soil at some point and play a beneficial role in maintaining the soil fertility. Figure 2 showing the soil enzyme activities in presence of RA and SN13 inoculated with and without pesticides spray. Both the PGPR play an important role in maintaining the soil enzyme activities and reduced the negative effect of pesticides in soil health.
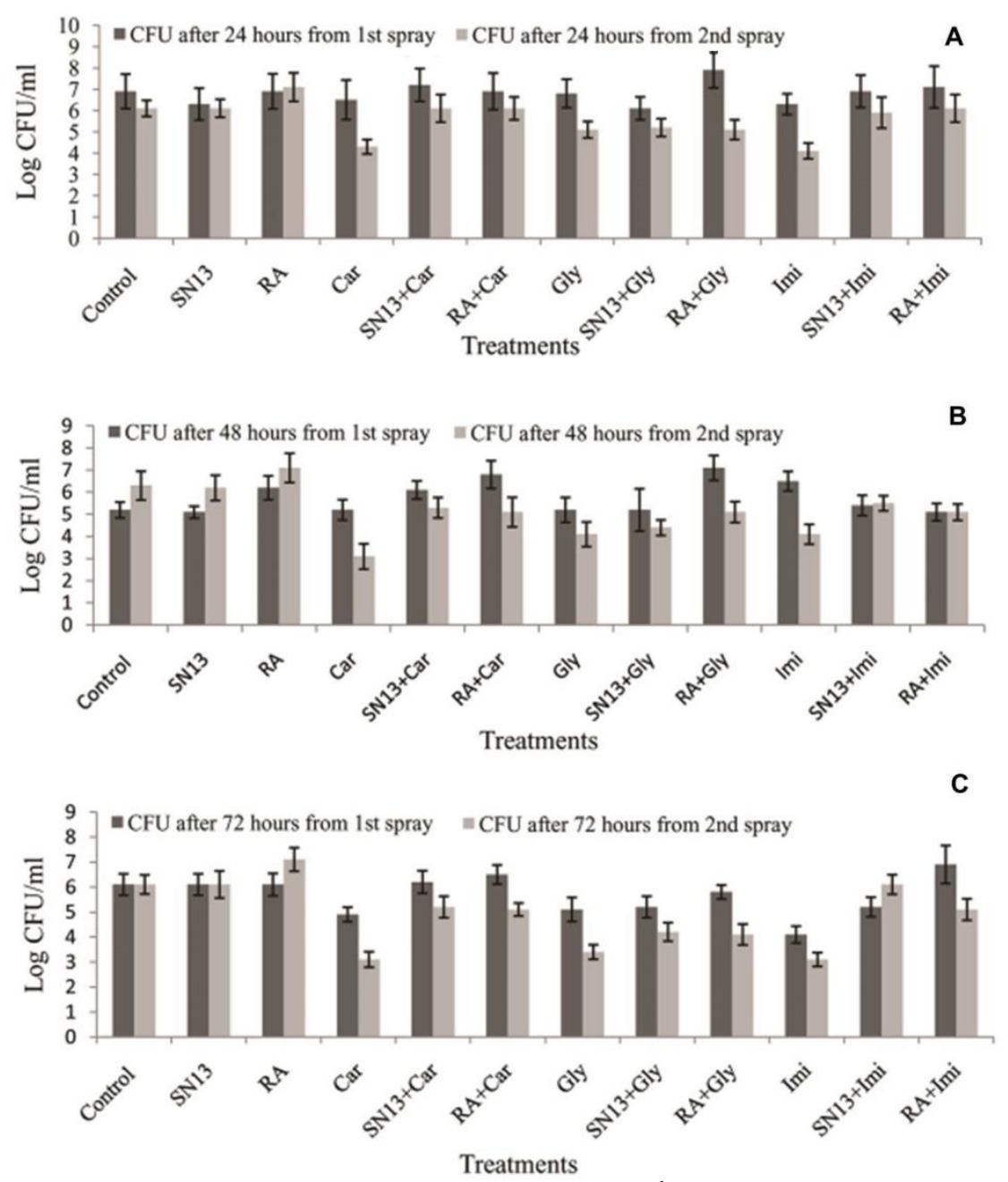

Figure 3. Colony forming unit assay: A, CFU after $24 \mathrm{hrs}$ from $1^{\text {st }}$ and $2^{\text {nd }}$ spray of pesticides; B, CFU assay after $48 \mathrm{hrs}$ from $1^{\text {st }}$ and $2^{\text {nd }}$ spray of pesticides; $\mathbf{C}, \mathrm{CFU}$ after $72 \mathrm{hrs}$ from $1^{\text {st }}$ and $2^{\text {nd }}$ spray of pesticides. [bars represent the standard errors of the means $(\mathrm{n}=3)]$

\section{CFU assay in pesticide treated soil}

CFU of rhizosphere soil was measured after 24,48 and $72 \mathrm{hrs}$ from $1^{\text {st }}$ and $2^{\text {nd }}$ spray of pesticides. The numbers of viable colonies were higher in RA inoculated than control soil samples with and without pesticides treatments. The decreased colonies were observed in Car, Imi and Gly treated soil samples after first and second spray whereas colonies were increased in RA and SN13 inoculated soil samples (Fig. 3). Pesticides treated 
samples showed a reduction in CFU values after $72 \mathrm{hrs}$ of $1^{\text {st }}$ spray and after $48 \mathrm{hrs}$ of $2^{\text {nd }}$ spray. Samples with PGPR inoculations and with pesticides sprays showed relative less reduction in CFU values. These results (Fig. 3) revealed that the RA and SN13 reduced the adverse effect of pesticides and survival of bacteria is increased.

Biolog assay in pesticide-treated soil

Average well color development (AWCD) was calculated which showed the microbial activity in each well of the microplate. Microbial diversity indices like Shannon, McIntosh and Simpson functional diversity and related evenness have been determined (Table 4). These results revealed the bacterial population in the rhizosphere after pesticides spray. The Shannon and McIntosh diversity together with their evenness were reduced in Gly treated samples in presence of both bacterial strains. But in case of Car and Imi samples diversity indices were not changed with and without inoculation of RA and SN13.

Table 4. Functional diversities and evenness based on carbon source utilization pattern for chickpea rhizosphere treated with Pseudomonas putida (RA) and Bacillus amyloliquefaciens (SN13) with and without pesticides treatment.

\begin{tabular}{llrrrrr}
\hline S.No. & Sample & ShD & ShE & ShipD & McD & McE \\
\hline $\mathbf{1}$ & Control & $3.34 \pm 0.02$ & $0.99 \pm 0.01$ & $0.99 \pm 0.00$ & $0.98 \pm 0.00$ & $0.99 \pm 0.00$ \\
$\mathbf{2}$ & RA & $3.33 \pm 0.02$ & $0.98 \pm 0.00$ & $0.99 \pm 0.00$ & $0.98 \pm 0.00$ & $0.99 \pm 0.00$ \\
$\mathbf{3}$ & SN13 & $3.31 \pm 0.03$ & $0.97 \pm 0.00$ & $0.99 \pm 0.00$ & $0.98 \pm 0.01$ & $0.98 \pm 0.00$ \\
$\mathbf{4}$ & Car & $3.30 \pm 0.02$ & $0.96 \pm 0.00$ & $0.98 \pm 0.00$ & $0.98 \pm 0.00$ & $0.97 \pm 0.00$ \\
$\mathbf{5}$ & Gly & $3.21 \pm 0.01$ & $0.94 \pm 0.01$ & $0.97 \pm 0.00$ & $0.95 \pm 0.00$ & $0.96 \pm 0.00$ \\
$\mathbf{6}$ & Imi & $3.25 \pm 0.01$ & $0.95 \pm 0.00$ & $0.96 \pm 0.00$ & $0.98 \pm 0.00$ & $0.98 \pm 0.00$ \\
$\mathbf{7}$ & RA+Car & $3.31 \pm 0.01$ & $0.97 \pm 0.00$ & $0.99 \pm 0.00$ & $0.98 \pm 0.00$ & $0.98 \pm 0.00$ \\
$\mathbf{8}$ & RA+Gly & $3.22 \pm 0.02$ & $0.95 \pm 0.01$ & $0.99 \pm 0.00$ & $0.97 \pm 0.00$ & $0.97 \pm 0.01$ \\
$\mathbf{9}$ & RA+Imi & $3.27 \pm 0.01$ & $0.96 \pm 0.01$ & $0.99 \pm 0.00$ & $0.97 \pm 0.00$ & $0.98 \pm 0.00$ \\
$\mathbf{1 0}$ & SN13+Car & $3.33 \pm 0.01$ & $0.98 \pm 0.01$ & $0.99 \pm 0.00$ & $0.98 \pm 0.00$ & $0.99 \pm 0.00$ \\
$\mathbf{1 1}$ & SN13+Gly & $3.18 \pm 0.03$ & $0.95 \pm 0.01$ & $0.99 \pm 0.00$ & $0.96 \pm 0.00$ & $0.97 \pm 0.01$ \\
$\mathbf{1 2}$ & SN13+Imi & $3.30 \pm 0.01$ & $0.96 \pm 0.00$ & $0.99 \pm 0.00$ & $0.98 \pm 0.00$ & $0.98 \pm 0.00$ \\
\hline
\end{tabular}

Note: ShD, Shannon diversity; ShE, Shannon evenness; SimpD, Simpson diversity; McD, McIntosh diversity; McE, McIntosh evenness.

\section{DISCUSSION}

Pseudomonas putida and Bacillus amyloliquefaciens are well known for their PGP attributes. Production of IAA, EPS and biofilm by these bacteria were maximum at threshold concentrations of pesticides but above that production was reduced (Table 2). Pesticide uses may cause slight and temporary changes to microbial populations of soil and their activities even if applied at normal rates (Johnsen et al. 2001). In case of repeated application pesticides can interfere and disturb soil enzymatic activities and also affected local metabolism resulting a reduction in soil fertility. Soil dehydrogenases are the enzymes belong to oxidoreductase enzyme class and are its major representatives (Gu et al. 2009). Dehydrogenases are very important enzymes in the soil environment which are an indicator of the overall microbial activity of soil (Gu et al. 2009, Salazar et al. 2011). These occur intracellularly in all microbial cells (Yuan \& Yue 2012). Dehydrogenase enzyme activity is repeatedly performed for measurement of any disturbance due to pesticides, or direct measure of soil microbial activity and trace elements or management practices to the soil. Our results revealed that dehydrogenase activity was inhibited in Car and Gly treated samples whereas Imi didn't affect this activity (Fig. 2). This enzyme activity was higher in the sample inoculated with RA and SN13 alone without pesticides than control. Phosphatases have five main groups of enzymes: phosphomonoesterases, phosphodiesterases, phosphotriesterases, phosphoamidases and pyrophosphatases. Among these five enzymes, phosphomonoesterases are most abundant in soils. This may be because of low substrate specificity of this group of enzymes (De Cesare et al. 2000). Phosphomonoesterases are further classified into two groups which are acid and alkaline phosphatase, on the basis of optimum $\mathrm{pH}$ for their activity. These two phosphatases are mainly found in animals and microorganisms. It was found by researchers that alkaline phosphatase activity gets inhibited when the fungicide is applied to soil (Rasool \& Reshi 2010), while the activity of acid phosphatase increased. Acid phosphatase activity was observed highly inhibited immediately after Car addition compared to the control (Tortella et al. 2013). Researchers also found that other fungicides either had inhibited phosphatases activity or no effect (Bello et al. 2008, Yan et al. 2011). On the application of herbicides the activity of acid and alkaline phosphatase is either stimulated (imazethapyr) or unchanged (aurora $40 \mathrm{WG}$ and rimsulfuron) (Perucci et al. 2000, Baćmaga et al. 2012). Phosphatases activities were found to be inhibited by herbicide application under different conditions of soil physicochemical properties and pesticides dose (Min et al. 2001, Tejada www.tropicalplantresearch.com 
2009). The acid and alkaline phosphatase activities may respond differently to application of insecticides. Sometimes the same insecticide may inhibit acid phosphatase and stimulate the activity of alkaline phosphatase, and vice versa (Cycon et al. 2010, Defo et al. 2011, Jastrzebska 2011). Overall it was found in earlier studies that pesticides play an inhibitory effect on the enzymatic activities involved in the phosphorus cycle. We found enhanced acid phosphatase activity in samples treated with Car and Gly whereas this activity was inhibited in by Imi. For bacterized samples treated with a recommended concentration of pesticides, an overall increase in acid phosphatase activity was observed for both the PGPR. $\beta$-glucosidase is an enzyme which plays important role in the decomposition/transformation of organic matter in the soil. Glucose is the final product which is an important source of carbon energy for soil microorganisms (Deng \& Tabatabai 1994). In our results, $\beta$ glucosidase activity was found inhibited in samples treated with Car, Gly and Imi. This activity was found higher in RA and SN13 inoculated soil samples than control.

Hydrolysis of urea into carbon dioxide and ammonia is catalyzed by urease. Researchers have proven that herbicides and fungicides appear to have no effect (Cycon et al. 2010, Yan et al. 2011, Baćmaga et al. 2012) or reduced effect on the activity of urease (Sukul 2006, Caceres et al. 2009, Tejada 2011). Application of pesticides decreases the urease activity in the soil which is beneficial for plants by reducing the hydrolysis of urea because it helps to maintain nitrogen availability to plant (Antonious 2003). On the other hand, the fungicides validamycin and Car enhanced urease activity, respectively, up to 13-21\% and to 70\% (Qian et al. 2007, Yan et al. 2011). In our experiment, we found inhibited urease activity by Gly and Imi whereas stimulated with Car. Protease enzyme plays an important role in nitrogen mineralization which regulates the amount of available nitrogen to the plants. The protease activity was found to be higher after the application of endosulfan and chlorpyrifos at lower and medium concentrations. Pesticides applications had stimulated the activity of protease enzyme in comparison to control upto 21 days from incubation (Rasool \& Reshi 2010). Protease activity in soil decreased on applications of insecticides on concentration more than 25 ppm. Our results revealed that protease activity was found stimulated in samples containing Car and Imi whereas reduced activity was found in Gly treated soil samples. In overall experiments, it was common observations results for second sprays were more drastic revealing that repeated use of chemicals leached to the soil and disturb the microbial population and changed the soil enzyme activities. PGPR (RA and SN13) inoculation has reduced the adverse effect by maintaining the microbial population and metabolic activities.

In biolog technique, the rate of colour development in wells provides information about the density and metabolic activity of bacterial cells in an inoculum, while the diversity of colour development in wells about microbial diversity in soil solution (Mondini \& Insam 2003). We have concluded from the diversity study that with the use of pesticides a slight reduction in microbial diversity and evenness was observed but the sample inoculated with PGPR showed no such changes due to the survival of microbial population and poise of soil enzymes.

\section{CONCLUSIONS}

Our experimental evidences concluded that repeated application of pesticides disturb soil microbial dynamics. An increase in PGP trait activities like IAA production, exopolysachchride production, biofilm synthesis, phosphate solubilization and siderophore production on the addition of pesticides at concentrations below threshold values. Inoculation of P. putida and B. amyloliquefaciens maintain the equilibrium of microbial population in soil and also balance soil enzymatic activities. Thus the application of pesticides (Car, Imi and Gly) under PGPR (RA and SN13) inoculated soil would not reduce microbial population hence improve soil fertility.

\section{ACKNOWLEDGEMENT}

This research was financially supported by New Initiative (as a Cross Flow Technology project) "Root Biology and Its Correlation to Sustainable Plant Development and Soil Fertility" (Root SF, BSC0204) from the Council of Scientific and Industrial Research (CSIR), New Delhi, India.

\section{REFERENCES}

Ahemad M \& Kibret M (2013) Mechanisms and applications of plant growth promoting rhizobac-teria: Current perspective. Journal of King Saud University Science 26(1): 1-20.

Alef K \& Nannipieri P (1995) Enzyme activities. In: Alef K \& Nannipieri P (eds) Methods in applied, Soil 
Microbiol Biochem. Academic Press, London- New York San Francisco, pp.xix + 576 p.

Andrabi M, Vaid A \& Razdan VK (2011) Evaluation of different measures to control wilt causing pathogens in chickpea. Journal of Plant Protection Research 51(1): 55-59.

Antonious GF (2003) Impact of soil management and two botanical insecticides on urease and invertase activity. Journal of Environmental Science and Health Part B 38: 479-488.

Baćmaga M, Boros E, Kucharski J \& Wyszkowska J (2012) Enzymatic activity in soil contaminated with the aurora $40 \mathrm{wg}$ herbicide. Environment Protection Engineering Journal 38(1): 91-102.

Bello D, Trasar-Cepeda C, Leiros MC \& Gil-Sotres F (2008) Evaluation of various tests for the diagnosis of soil contamination by 2,4,5-trichlorophenol (2,4,5-TCP). Environmental Pollution 156: 611-617.

Berendsen RL, Pieterse CM \& Bakker PA (2012) The rhizosphere microbiome and plant health. Trends in Plant Science 17: 478-486.

Brick JM, Bostock, RM \& Silverstone, SE (1991) Rapid in situ assay for indole acetic acid production by bacteria immobilized on nitrocellulose membrane. Applied and Environmental Microbiology 57: 535-538.

Buffin D (2005) Pesticide Action Network UK (PAN international). Available from: http://www.panuk.org/pestnews/Archives/imidaclo.htm (accessed: 17 Feb. 2006).

Caceres TP, He WX, Megharaj M \& Naidu R (2009) Effect of insecticide fenamiphos on soil microbial activities in Australian and Ecuadorean soils. Journal of Environmental Science and Health Part B 44: 13-17.

Cycon M, Piotrowska-seget Z \& Kozdroj J (2010) Response of indigenous microorganisms to a fungicidal mixture of mancozeb and dimethomorph added to sandy soils. International Biodeterioration and Biodegradation 64: 316-323.

De Cesare F, Garzillo AMV, Buonocorea V \& Badalucco L (2000) Use of sonication for measuring acid phosphatase activity in soil. Soil Biology and Biochemistry 32: (6) 825-832.

Defo MA, Njine T, Nola M \& Florence SB (2011) Microcosm study of the long term effect of endosulfan on enzyme and microbial activities on two agricultural soils of Yaounde-Cameroon. African Journal of Agricultural Research 6(9): 2039-2050.

Deng SP \& Tabatabai MA (1994) Colorimetric determination of reducing sugars in soils. Soil Biochemistry $26:$ 473-477.

Dong YJ, Bartlam M, Sun L, Zhou YF, Zhang ZP, Zhang CG, Rao ZH \& Zhang XE (2005) Crystal structure of methyl parathion hydrolase from Pseudomonas sp WBC-3. Journal of Molecular Biology 353: 655-663.

Dubois M, Gilles KA, Hamilton JK, Rebers PA \& Smith F (1956) Calorimetric method for determination of sugars and related substances. Analytical Chemistry 28: 350-356.

Duke SO (2005) Taking stock of herbicide-resistant crops ten years after introduction. Pest Management Science 61: 211-218.

Eivazi F \& Tabatabai MA (1988) Glucosidases and galactosidases in soils. Soil Biology and Biochemistry 20: 601-606.

Engelen B, Meinken K, Von- Wintzintgerode F, Heuer H, Malkomes HP \& Backhaus H (1998) Monitoring impact of a pesticide treatment on bacterial soil communities by metabolic and genetic fingerprinting in addition to conventional testing procedures. Applied and Environmental Microbiology 64: 2814-2821.

Figueiredo MDVB, Seldin L, de Araujo FF \& Mariano RLR (2011) Plant growth promoting rhizobacteria: fundamentals and applications. In: Maheshwari DK (ed) Plant Growth and Health Promoting Bacteria. Springer, Berlin, Heidelberg, pp. 21-43.

Gianfreda L \& Bollag JM (1994) Effect of soils on the behavior of immobilized enzymes. Soil Science Society of America Journal 58(6): 1672-1681.

Gianfreda L \& Rao MA (2008) Interactions between xenobiotics and microbial and enzymatic soil activity. Critical Reviews in Environmental Science and Technology 38(4): 269-310.

Gil-Sotres F, Trasar-Cepeda C, Leiros MC \& Seoane S (2005) Different approaches to evaluating soil quality using biochemical properties. Soil Biology and Biochemistry 37(5): 877-887.

Gordon S \& Weber RA (1951) Colorimetric estimation of Indoleacetic acid. Plant Physiology 26: 192-195.

Grube A, Donaldson D, Kiely T \& Wu L (2011) Pesticides Industry Sales and Usage. US EPA, Washington, DC. Global Industry Analysts, 2011. Global Glyphosate Market to Reach 1.35 Million Metric Tons by 2017, According to a New Report by Global Industry Analysts, Inc.

Gu Y, Wag P \& Kong C (2009) Urease, Invertase, Dehydrogenase and Polyphenoloxidase activities in paddy soils influenced by allelophatic rice variety. European Journal of Soil Biology 45: 436-441.

www.tropicalplantresearch.com 
Gupta A, Gopal M \& Tilak K (2000) Mechanism of plant growth promotion by rhizobacteria. Indian Journal of Experimental Biology 38: 856-862.

Hernandez-Rodriguez D, Sanchez JE, Nieto MG \& Marquez-Rocha FJ (2006) Degradation of endosulfan during substrate preparation and cultivation of Pleurotus pulmonarius. World Journal of Microbiology and Biotechnology 22: 753-760.

Hussain S, Siddique T, Saleem M, Arshad M \& Khalid A (2009) Impact of pesticides on soil microbial diversity, enzymes, and biochemical reactions. Advances in Agronomy 102: 159-200.

IIPR (2010-11) Indian Institute of Pulses Research. Annual Report 2010-2011. Kanpur, India.

Ishaaya I \& Horowitz AR (eds) (1998) Insecticides with Novel Modes of Action: Mechanisms and Applications. Springer-Verlag Press, Berlin.

Jastrzebska E (2011) The effect of Chloropyriphos and Teflubenzuron on the enzymatic activities of soil. Polish Journal of Environmental Studies 20: 903-910.

Johnsen K, Jacobsen CS, Torsvik V \& Sorensen J (2001) Pesticide effects on bacterial diversity in agricultural soils-a review. Biology and Fertility of Soils 33: 443-453.

Kalam A, Tah J \& Mukherjee AK (2004) Pesticide effects on microbial population and soil enzyme activities during vermicomposting of agricultural waste. Journal of Environmental Biology 25: 201-208.

Kandeler E \& Gerber H (1988) Short-term assay of soil urease activity using colorimetric determination of ammonium. Biology and Fertility of Soils 16: 249-254.

Khan N, Mishra A, Chauhan PS, Sharma YK \& Nautiyal CS (2012) Paenibacillus lentimorbus enhances growth of chickpea (Cicer arietinum L.) in chromium-amended soil. Antonie Van Leeuwenhoek 101(2): 453-459.

Kumar M, Mishra S, Dixit VK, Kumar M, Agrawal L, Chauhan PS \& Nautiyal CS(2016) Synergistic effect of Pseudomonas putida and Bacillus amyloliquefaciens ameliorates drought stress in chickpea. Plant Signaling and Behaviour 11(1): e1071004.

Ladd JN \& Butler JH (1972) Short-term assays of soil proteolytic enzyme activities using proteins and dipeptide derivatives as substrates. Soil Biology and Biochemistry 4: 19-30.

Liu XM, Li Q, Liang WJ \& Jiang Y (2008) Distribution of soil enzyme activities and microbial biomass along a latitudinal gradient in farmlands of songliao plain, Northeast China. Pedosphere 18(4): 431-440.

Lo C-C (2010) Effect of pesticides on soil microbial community. Journal of Environmental Science and Health Part B 45: 348-359.

Malkomes HP \& Dietze T (1998) Effects of steaming and pesticides on soil microorganisms under laboratory conditions. II. Effects of partial sterilization and its combination with pesticides. Research Journal of Agriculture and Biological Sciences 51: 155-165.

Matsuda K, Buckingham SD \& Kleier D (2001) Neonicotinoids: insecticides acting on insect nicotinic acetylcholine receptors. Trends in Pharmacological Sciences 22: 573-579.

Menon P, Gopal M \& Parsad R (2005) Effects of chlorpyrifos and quinalphos on dehydrogenase activities and reduction of $\mathrm{Fe} 3$ ? In the soils of two semi-arid fields of tropical India. Agriculture Ecosystem and Environment 108: 73-83.

Meyer JM \& Abdallah MA (1978) The fluorescent pigment of Pseudomonas fluorescens: biosynthesis, purification, and physiochemical properties. Journal of general Microbiology 10: 319-328.

Mijangos I, Becerril JM, Albizu I, Epelde L \& Garbisu C (2009) Effects of glyphosate on rhizosphere soil microbial communities under two different plant compositions by cultivation-dependent and -independent methodologies. Soil Biology and Biochemistry 41: 505-513.

Min H, Hang YY,Yun CZ \& Xiang WW \& Du Y (2001) Effect of butachlor on microbial populations and enzyme activities in paddy soil. Journal of Environmental Science and Health 36(5): 581-595.

Mishra JS, Moorthy BTS \& Bhan M (2005) Efficacy of Herbicides Against Field Dodder (Cuscuta campestris) in Lentil, Chickpea and Linseed, Indian 1. Weed Science 37 (3\&4): 220-224.

Mondini C \& Insam H (2003) Community level physiological profiling as a tool to evaluate compost maturity: a kinetic approach. European Journal of Soil Biology 39(3): 141-148.

Monkiedje A \& Spiteller M (2002) Effects of the phenylamide fungicides, mefenoxam and metalaxyl, on the microbiological properties of a sandy loam and a sandy clay soil. Biology and Fertility of Soils 35: 393-398.

Nauen R \& Denholm I (2005) Resistance of insect pests to neonicotinoid insecticides: current status and future prospects. Archives of Insect Biochemistry and Physiology 58: 200-215.

Nautiyal CS (1997) Rhizosphere competence of Pseudomonas sp. NBRI9926 and Rhizobium sp. NBRI9513

www.tropicalplantresearch.com 
involved in the suppression of chickpea (Cicer arietinum L.) pathogenic fungi. FEMS Microbial Ecology 23: $145-158$.

Nautiyal CS (1999) An efficient microbiological growth medium for screening phosphate solubilizing microorganisms. FEMS Microbiol Letters 170: 265-270.

Neumann G, Kohls S, Landsberg E, Stock-Oliveira Souza K, Yamada T \& Römheld V (2006) Relevance of glyphosate transfer to non-target plants via the rhizosphere. Journal of Plant Diseases and Proctection, Supplement pp. 963-969.

Perucci P \& Scarponi L (1994) Effects of the herbicide imazethapyr on soil microbial biomass and various soil enzyme-activities. Biology and Fertility of Soils 17: 237-240.

Perucci P, Casucci C \& Dumontet S (2000) An improved method to evaluate the o-diphenol oxidase activity of soil. Soil Biology and Biochemistry 32(1): 387-399.

Qian H, Hu B, Wang Z, Xu X \& Hong T (2007) Effects of validamycin on some enzymatic activities in soil Environmental Monitoring and Assessment 125: 1-8.

Rao P, Birthal PS, Bhagavatula S \& Bantilan MCS (2010) Chickpea and Pigeonpea Economies in Asia: Facts, Trends and Outlook. International Crops Research Institute for the Semi-Arid Tropics, Patancheru 502324, Andhra Pradesh, India, pp 76.

Rasool LN \& Reshi Z (2010) Effect of the fungicide Mancozeb at different application rates on enzyme activities in a slit loam soil of the Kashmir Himalaya, India. Tropical Ecology 51(2) 199-205.

Reddy AA \& Reddy GP (2010) Supply side constraints in production of pulses in India: A case study of lentil. Agricultural Economics Research Review 23: 129-136.

Ronhede S, Sorensen SR, Jensen B \& Aamand J (2007) Mineralization of hydroxylate disoproturon metabolites produced by fungi. Soil Biology and Biochemistry 39: 1751-1758.

Salazar S, Sanchez L, Alvarez J, Valverde A, Galindo P, Igual J, Peix A \& Santa-Regina I (2011) Correlation among soil enzyme activities under different forest system management practices. Ecological Engineering 37: 1123-1131.

Sheng M, Hamel C \& Fernandez MR (2012) Cropping practices modulate the impact of glyphosate on arbuscularmycorrhizal fungi and rhizosphere bacteria in agroecosystems of the semiarid prairie. Canadian Journal of Microbiology 58: 990-1001.

Sukul P (2006) Enzymatic activities and microbial biomass in soil as influenced by metalaxyl residues. Soil Biology and Biochemistry 38: 320-326.

Tabatabai A (1994) Soil enzymes. In: Weaver RW, Angle JS \& Bottomley PS (eds) Methods of Soil Analysis, Part 2. Microbiological and Biochemical Properties, second ed. Soil Science Society of America, Madison, WI, USA, pp. 775-833.

Tabatabai MA \& Bremner JM (1969) Use of p-nitro phenyl phosphate for assay of soil phosphatase activity. Soil Biology and Biochemistry 1: 301-307.

Tejada M (2009) Evolution of soil biological properties after addition of glyphosate, diflufencian and glyphosate + diflufencian herbicides. Chemosphere 76: 365-373.

Tejada M, Benítez C, Gómez I \& Parrado J (2011) Use of bio stimulants on soil restoration: Effects on soil biochemical properties and microbial community. Applied Soil Ecology 49: 11-17.

Tortella GR, Mella-Herrera RA, Sousa DZ, Rubilar O, Briceño G, Parra L \& Diez MC (2013) Carbendazim dissipation in the biomixture of on-farm biopurification systems and its effect on microbial communities. Chemosphere 93: 1084-1093.

Yan Y, Yang Y, You J, Yang G, Xu Y, Huang N, Wang X, Ran D, Yuan X, Jin Y, Fan Y, Lei J, Li W \& Gu H (2011) Permethrin modulates cholinergic mini-synaptic currents by partially blocking the calcium channel. Toxicology Letters 201(3): 258-263.

Yogeeswarudu B \& Venkata-Krishna K (2014) Field studies on efficacy of novel insecticides against Helicoverpa armigera (Hubner) infesting on Chickpea. Journal of Entomology and Zoology Studies 2(4): 286-289.

Yuan B \& Yue D (2012) Soil microbial and enzymatic activities across a chronosequence of chinese pine plantation development on the loess plateau of china. Pedosphere 22: 1-12. 